\title{
ANALISIS REGRESI ALAT UKUR EMISI GAS KARBON MONOKSIDA BERBASIS ARDUINO UNO
}

\author{
Azhari $^{\text {la }}$, Lukman Hakim ${ }^{2 \mathrm{a}}$ \\ 1,2 Departemen Fisika FMIPA Universitas Sumatera Utara, Medan, Indonesia \\ ${ }^{a}$ Lab. Penelitian Terpadu Universitas Sumatera Utara, Medan, Indonesia \\ Corresponding author email: azhari@usu.ac.id
}

\author{
Info Artikel \\ Diterima: \\ 27 April 2020 \\ Disetujui: \\ 5 Juni 2020 \\ Dipublikasikan: \\ 15 Juni 2020
}

\begin{abstract}
Abstrak:
Keberadaan zat polutan merupakan ancaman serius dalam kesehatan. Salah satu zat polutan dalam mempengaruhi kualitas udara adalah gas karbonmonoksida. Sebagian besar karbon monoksida berasal dari emisi gas buang kendaraan bermotor. Tujuan dari penelitian ini adalah untuk membuat alat ukur emisi gas karbonmonoksida kendaraan bermotor menggunakan sensor gas TGS 822. Metode penelitian ini dimulai dengan desain perangkat keras menggunakan sensor gas TGS822 sebagai sensor gas karbonmonoksida kemudian diproses dengan mikrokontroller arduino uno dan transfer data oleh Bluetooth. Hasil pembacaan nilai polutan kemudian diproses dengan mikrokontroler dan ditampilkan dalam layar komputer dengan menggunakan konektor bluetooth sehingga bisa dipantau secara realtime. Data yang didapat dari hasil pengujian kemudian dianalisis menggunakan persamaan regresi dengan membandingkan dengan data hasil pembacaan alat ukur standar. Hasil dari pengujian alat menunjukkan nilai persamaan regresi $\mathrm{y}=$ $0,0641 \mathrm{x} \pm 38.438$ dengan nilai $\mathrm{R}^{2}=0,9997$. Hasil tersebut menunjukkan korelasi yang kuat antara data dari CO meter dengan alat ukur emisi gas $\mathrm{CO}$ yang dibuat.
\end{abstract}

Kata kunci: Sensor gas, karbon monoksida, Arduino Uno

\section{Abstract :}

The presence of pollutants is a serious threat to health. One of the pollutants in influencing air quality is carbon monoxide gas. Most of the carbon monoxide comes from motor vehicle exhaust emissions. The purpose of this research is to make a vehicle carbon monoxide gas emission measurement tool using the TGS 822 gas sensor. The research method begins with the hardware design using the TGS822 gas sensor as a carbon monoxide gas sensor then processed with an arduino uno microcontroller and data transfer by bluetooth. The results of the reading of pollutant values are then processed with a microcontroller and displayed on a computer screen using a Bluetooth connector so that it can be monitored in real time. Data obtained from the test results are then analyzed using a regression equation by comparing with data from the reading of standard measuring instruments. The results of testing the instrument shows the value of the regression equation $y=-0,0641 x \pm$ 38.438 with a value of $R^{2}=0$, 9997. These results show a strong correlation between the data from the $\mathrm{CO}$ meter with the $\mathrm{CO}$ gas emission gauge that has been made.

Keywords: Gas sensor, carbon monoxide, Arduino Uno 


\section{Pendahuluan}

Setiap tahunnya WHO melaporkan bahwa sekitar 7 juta kematian atau 1/8 kematian global disebabkan oleh polusi udara. Data tersebut juga merilis bahwa 9 dari 10 orang diseluruh dunia menghirup udara yang mengandung polutan tingkat tinggi (WHO, 2019). Beberapa negara dan kota besar telah menerapkan berbagai kebijakan untuk mengurangi dampak pencemaran udara ini (BBC, 2019). Beberapa studi yang telah dilakukan termasuk penelitian yang merancang perangkat uji emisi gas secara real time dan dipantau melalui web (Suyuti, 2013).

Berdasarkan Keputusan Menteri Kesehatan Republik Indonesia nomor 1407 tahun 2002 tentang Pedoman Pengendalian Dampak Pencemaran Udara, pencemaran udara dapat didefinisikan dengan masuk atau dimasukkannya zat, energi, dan/atau komponen lain ke dalam udara oleh aktivitas manusia, sehingga kualitas udara turun ke tingkat tertentu yang menyebabkan atau mempengaruhi kesehatan manusia.Peningkatan perkembangan industri dan peningkatan populasi akan menghasilkan jumlah jenis transportasi yang memiliki pengaruh pada kualitas udara dalam pengaturan perkotaan (Mukono, 2011).

Karbon monoksida $(\mathrm{CO})$ adalah polutan. Berdasarkan perkiraan, jumlah $\mathrm{CO}$ di Indonesia diperkirakan mendekati 60 juta ton / tahun. Seperdelapan dari jumlah ini berasal dari kendaraan bermotor yang menggunakan bensin dan sepertiga dari sumber tidak bergerak. Padahal karbon monoksida adalah gas yang mudah terbakar dan sangat beracun bagi manusia. Dalam laporan Organisasi Kesehatan Dunia, WHO diperkirakan bahwa setidaknya satu jenis polusi udara di kota-kota besar telah melampaui batas toleransi polusi udara.

Kendaraan bermotor merupakan sumber polutan CO yang utama (sekitar 59,2\%), daerahdaerah yang berpenduduk padat dengan lalu lintas ramai memperlihatkan tingkat polusi CO yang tinggi. Konsentrasi CO di udara per waktu dalam satu hari dipengaruhi oleh kesibukan atau aktivitas kendaraan bermotor yang ada. Semakin ramai kendaraan bermotor yang ada, semakin tinggi tingkat polusi CO di udara (Prabowo \& Muslim, 2018). Gas karbon monoksida (CO) merupakan polutan yang sangat berbahaya dari kendaraan bermotor dan dapat mengganggu kesehatan manusia sehingga menjadi parameter parameter dari pencemaran udara yang ada di sekitar.

Gas CO utamanya dihasilkan dari pembakaran tidak sempurna yang sangat mungkin terjadi pada kendaraan bermotor. Secara teori, pembakaran tidak sempurna terjadi karena kekurangan oksigen dalam proses pembakaran. Kendaraan bermotor merupakan sumber utama CO, terutama bagi kendaraan yang sudah memiliki masa pakai yang lama, sehingga kondisi mesin kendaraan kurang berfungsi secara baik sehingga menghasilkan gas CO dengan konsentrasi besar (Basuki, 2008). Karena sifatnya yang tidak berbau, tidak berasa, dan tidak berwarna sangat sulit diketahui keberadaannya. Gas $\mathrm{CO}$ merupakan komponen gas yang sangat beracun karena lebih cepat mengikat hemoglobin menjadi carboxyhaemoglobin sehingga menyebabkan penghambatan aliran oksigen untuk mengikat hemoglobin (hb). Kekurangan suplai oksigen pada batas tertentu, yaitu pada meningkatnya resiko kematian (Zulfah, 2011).

Karbonmonoksida $(\mathrm{CO})$ merupakan gas yang relatif tidak stabil dan cenderung bereaksi dengan elemen lain, $\mathrm{CO}$ dapat dengan mudah diubah menjadi karbondioksida $\left(\mathrm{CO}_{2}\right)$ dengan sedikit bantuan oksigen dan panas, $\mathrm{CO}$ diukur dalam satuan\% per volume atau dalam ppm tetapi dalam industri otomotif sesuai dengan alat ukur yang digunakan sering diukur dalam satuan\% per volume (Robert, 1993). Organisasi Kesehatan Dunia (WHO) menyatakan bahwa 2,4 juta orang meninggal setiap tahun dari penyebab yang secara langsung terkait dengan polusi udara.

\section{Metode Penelitian}

Penelitian ini menggunakan adalah penelitian kuantitatif yang dilaksanakan pada bulan Oktober 2019 di kota Laboratorium Fisika Komputasi Departemen Fisika USU dan bekerja sama dengan Enviro Shafeera Laboratorium sebagai tempat pengujian gas CO. Sampel dalam penelitian ini adalah kendaraan roda 2 jenis sepeda motor Sport dengan nomor kendaraan BK 4440 YAK.

a. Prosedur Penelitian

Desain perangkat keras sistem pemantauan kualitas udara terdiri dari mikrokontroler Arduino Uno, sensor TGS 822, dan bluetooth. Secara umum, desain perangkat keras sistem adalah sebagai berikut: 
1. Sensor TGS 822 adalah sensor yang akan mendeteksi gas karbon monoksida yang direpresentasikan sebagai sensor gas CO.

2. Mikrokontroler Arduino Uno yang berfungsi sebagai pusat kendali untuk semua sensor.

3. Bluetooth yang berfungsi sebagai transmitter dan receiver dari data yang dibaca oleh sensor.

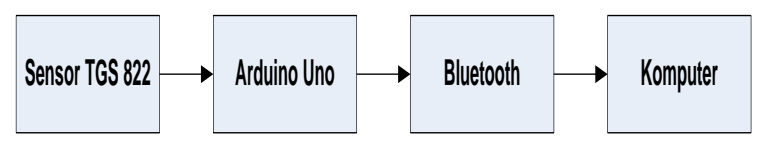

Gambar 1. Diagram Blok Sistem

\section{b. Rangkaian Mikrokontroler Arduino Uno}

Mikrokontroler Arduino adalah komponen utama yang berfungsi sebagai pusat pemrosesan data yang akan diproses sebelum dikirim ke viewer (komputer) melalui bluetooth. Komputer berfungsi sebagai penampil data yang diperoleh dari sensor sehingga bisa langsung dan data bisa disimpan secara realtime. Arduino adalah kit elektronik atau papan sirkuit elektronik open source di mana terdapat komponen utama, yaitu chip mikrokontroler dengan tipe AVR dari perusahaan Atmel. Bahasa pemrograman Arduino adalah bahasa C. Tetapi bahasa ini telah membuatnya lebih mudah untuk menggunakan fungsi-fungsi sederhana sehingga pemula dapat mempelajarinya dengan cukup mudah.

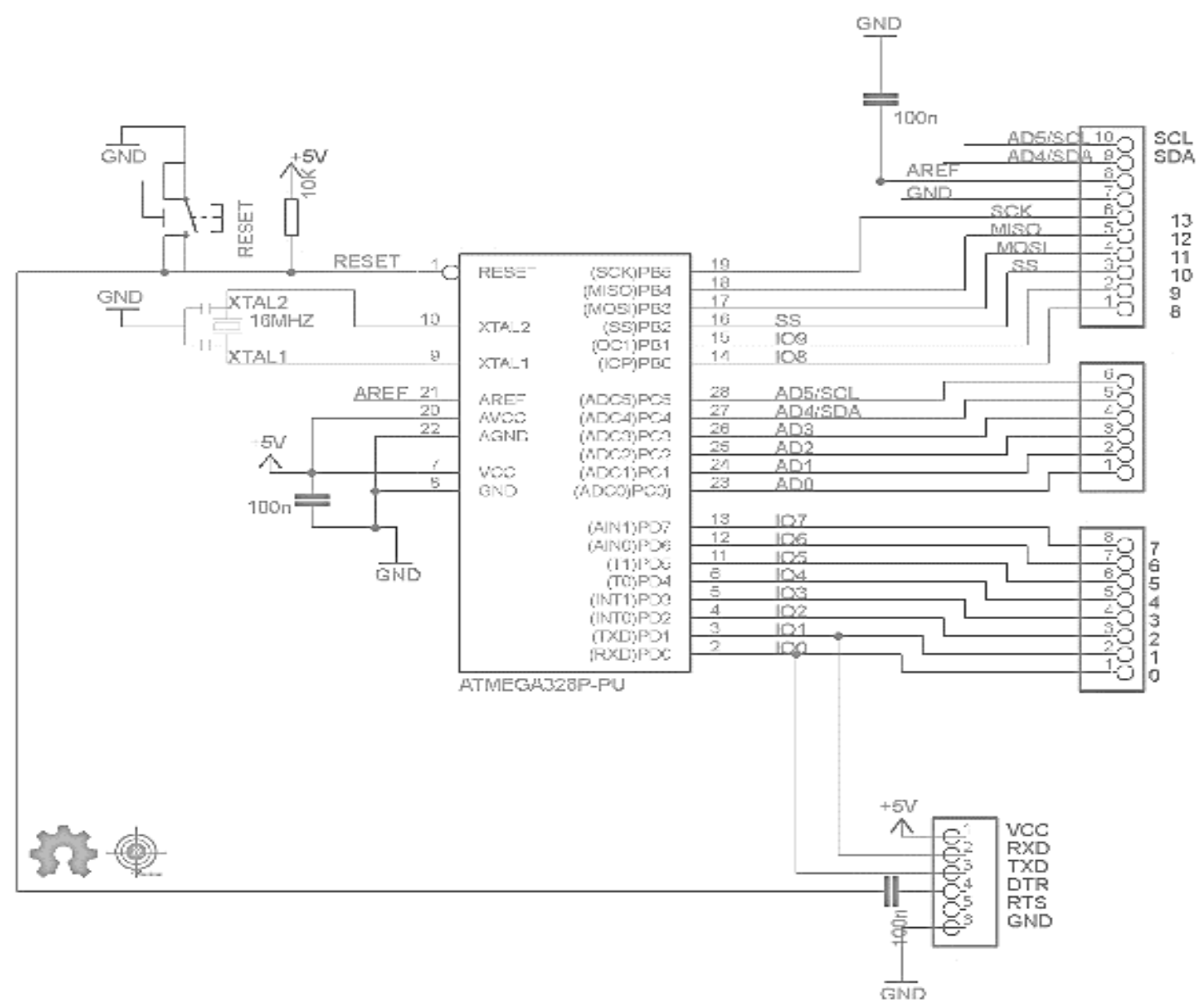

Gambar 2. Skema Mikrokontroller Arduino Uno (Sumber: www.electroschematics.com)

Alat pengukuran emisi gas buang kendaraan menggunakan Arduino Uno yang menggunakan mikrokontroler ATmega 328 sebagai pengontrol utama semua alat desain, termasuk hasil pengukuran sensor pembacaan dan perubahan hasil pengukuran sensor menjadi digital karena output sensor adalah analog. Dari gambar 2, mikrokontroler Arduino Uno diprogram menggunakan perangkat lunak Arduino IDE yang dikirim melalui port USB komputer. Catu daya yang digunakan adalah 9V yang terhubung pada 30 (VIN) dan 29 (GND). 


\section{c. Sirkuit Sensor TGS 822}

Elemen penginderaan sensor gas Figaro adalah semikonduktor timah dioksida ( $\mathrm{SnO} 2)$ yang memiliki konduktivitas rendah di udara bersih. Di hadapan gas terdeteksi, konduktivitas sensor meningkat tergantung pada konsentrasi gas di udara. Sirkuit listrik sederhana dapat mengubah perubahan konduktivitas menjadi sinyal keluaran yang sesuai dengan konsentrasi gas. TGS 822 memiliki sensitivitas tinggi terhadap uap pelarut organik serta uap volatil lainnya. Ini juga memiliki sensitivitas terhadap berbagai gas yang mudah terbakar seperti karbon monoksida, menjadikannya sensor tujuan umum yang baik.

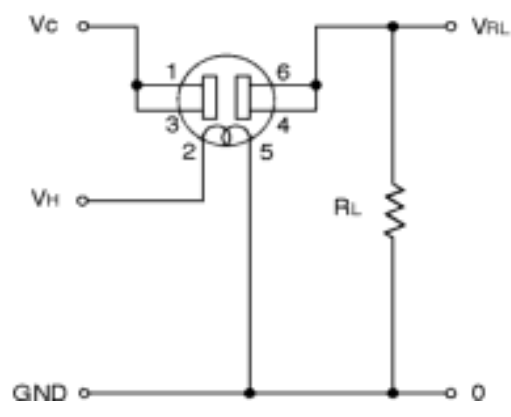

Gambar 3. Rangkaian Sensor TGS 822 (Sumber: www.researchgate.net/figure)

Struktur sensor ditunjukkan pada Gambar 3. TGS 822 adalah transduser utama yang digunakan dalam rangkaian ini, yang merupakan sensor gas. Sensor ini memiliki nilai resistansi Rs yang akan berubah ketika terkena gas dan juga memiliki pemanas yang digunakan untuk membersihkan ruang sensor dari kontaminasi udara luar. Desain perangkat lunak diperlukan karena untuk menjalankan sistem Arduino Uno, chip mikrokontroler ATMega 328 akan diisi dengan program perintah yang diinginkan.

\section{d. Teknik Analisis Data}

Tujuan kalibrasi adalah untuk mencapai keterlacakan pengukuran. Hasil pengukuran dapat ditelusuri ke standar yang lebih tepat. Dalam melakukan kalibrasi, dapat dilihat seberapa jauh perbedaan atau penyimpangan antara nilai sebenarnya dan nilai yang ditunjukkan oleh alat ukur. Selain itu, kalibrasi juga dilakukan untuk menentukan nilai ketidakpastian. Untuk mengetahui nilai atau ketidakpastian harga, yang merupakan langkah pertama untuk menemukan nilai standar deviasi, menggunakan persamaan 1 .

$$
\delta=\sqrt{\frac{\sum(x-\bar{x})^{2}}{n-1}}
$$

keterangan:

$\delta=$ standar deviasi

$\mathrm{n}=$ Jumlah data $\mathrm{x}$

Langkah kedua adalah menghitung nilai ketidakpastian dalam hasil pengukuran (UA 1), menggunakan persamaan 2.

$$
U A_{1}=\frac{\delta}{\sqrt{x}}
$$

Langkah ketiga adalah menghitung nilai ketidakpastian dari pendekatan regresi (UA 2). Tahapan untuk mencari nilai ketidakpastian dari pendekatan regresi (UA 2), yaitu pertama menggunakan persamaan regresi (Yreg), seperti pada persamaan 3.

$$
Y_{\text {reg }}=a+b x
$$

Untuk menghitung nilai persamaan regresi (Yreg), sebelumnya cari nilai a dan b. Tetapi untuk menemukan nilai a, harus menemukan nilai b terlebih dahulu seperti persamaan 4 .

$$
b=\frac{n \sum x y-\sum x \sum y}{n \sum x^{2}-\left(\sum x\right)^{2}}
$$


Agar setelah nilai b diketahui, maka selanjutnya hitung nilai a dengan persamaan 5.

$$
a=\bar{y}-b \bar{x}
$$

Setelah nilai persamaan regresi (Yreg) dihitung, maka langkah selanjutnya adalah mencari nilai Sum of Square Residual (SSR). Persamaan yang dapat digunakan untuk menemukan nilai SSR seperti pada persamaan 6.

$$
S S R=\sum(R)^{2}
$$

Setelah SSR diketahui, dapat dilanjutkan dengan menghitung ketidakpastian pendekatan regresi $\left(\mathrm{UA}_{2}\right)$ (Putro \& Abadi, 2012), menggunakan persamaan 7 berikut:

$$
U A_{2}=\sqrt{\frac{S S R}{n-2}}
$$

\section{Hasil Penelitian dan Pembahasan}

a. Pengujian Rangkaian Catu Daya

Catu daya merupakan bagian penting dalam suatu rangkaian, yaitu sebagai sumber tegangan. Catu daya yang dibutuhkan dalam sistem jangkauan ini adalah catu daya 5V DC. Sedangkan modul adaptor yang dipilih dalam penelitian ini adalah yang mudah ditemukan di pasaran adalah modul adaptor dengan output 12 Volt dengan arus 1 Ampere. Berikut ini adalah tabel pengujian modul adaptor :

Tabel 1. Pengujian Modul Adaptor

\begin{tabular}{cccc}
\hline No & $\begin{array}{c}\text { Nilai Tegangan } \\
(\mathbf{x})\end{array}$ & $\begin{array}{c}\text { Deviasi } \\
(\boldsymbol{x}-\overline{\boldsymbol{x}})\end{array}$ & $\begin{array}{c}\text { Kuadrat Deviasi } \\
(\boldsymbol{x}-\overline{\boldsymbol{x}})^{\mathbf{2}}\end{array}$ \\
\hline 1 & 12 & -0.466 & 0.217 \\
2 & 12.4 & $-0,066$ & 0.004 \\
3 & 13 & 0.534 & 0.285 \\
\hline & $\overline{\boldsymbol{x}}=\mathbf{1 2 . 4 6 6}$ & \multicolumn{2}{c}{$\Sigma(x-\bar{x})^{2}=0.506 \mathrm{~V}^{2}$} \\
\hline
\end{tabular}

Berdasarkan tabel di atas, didapatkan hasil tes catu daya dengan nilai rata-rata $(\bar{x})$ sebesar 12.466 volt dan nilai deviasi kuadrat $(x-\bar{x})^{2}$ adalah $0.506 V^{2}$. Kemudian nilai standar deviasi dihitung menggunakan persamaan 1 yaitu:

$$
\delta=\sqrt{\frac{\sum(x-\bar{x})^{2}}{n-1}}=\sqrt{\frac{0.506}{2}}=0.502 \text { Volt }
$$

Setelah mendapatkan nilai standar deviasi maka nilai tersebut dapat digunakan untuk menghitung nilai ketidakpastian. Adapun persamaan yang digunakan adalah persamaan 2, yaitu :

$$
U A_{1}=\frac{\delta}{\sqrt{n}}=\frac{0.502}{\sqrt{3}}=0.291 \text { Volt } \text {. }
$$

b. Pengujian Output Sensor Terhadap ADC

Pengujian sensor gas untuk mengetahui tegangan output besar yang dihasilkan oleh sensor untuk beberapa tes. Ini diperoleh karena nilai resistansi sensor menurun, menyebabkan tegangan output sensor (VRL) naik sesuai dengan besarnya level karbon monoksida (CO) yang terdeteksi oleh sensor. Untuk memvariasikan hasil pengukuran, sampel gas diberikan di sekitar sensor. Tegangan sensor diukur menggunakan multimeter digital. Pada alat ini menggunakan Analog to Digital Converter (ADC) yang sudah tersedia di mikrokontroler yaitu 10 bit. Hasil tes sensor bervariasi dengan tegangan output dan data output ADC. Tabel berikut menunjukkan tegangan yang keluar dari masing-masing sensor dan ADC. 
Tabel 2. Tegangan keluar dari sensor TGS 822 dan ADC

\begin{tabular}{ccccc}
\hline No & Tegangan & Rs & \multicolumn{2}{c}{ Data Output data pada ADC } \\
\cline { 4 - 5 } & Sensor $(\mathbf{V})$ & $(\mathbf{k} \boldsymbol{\Omega})$ & Binary & Desimal \\
\hline 1 & 0.8 & 52.5 & 0010100011 & 163 \\
2 & 1,1 & 35.45 & 0011100001 & 225 \\
3 & 1,3 & 28.46 & 0100001010 & 266 \\
4 & 1.5 & 23.33 & 0100110011 & 307 \\
5 & 1.8 & 17.77 & 0101110000 & 368 \\
\hline
\end{tabular}

Dalam alat ini, tegangan referensi yang digunakan dalam $A D C$ adalah $\mathrm{V}_{\text {ref }}=5$ volt dan resolusi $A D C$ 10 bit (1024), sehingga output ADC berdasarkan input dapat dihitung dengan persamaan berikut:

$$
\mathrm{ADC}=\frac{\text { Vout }}{\text { Vref }}(1024)
$$

c. Kalibrasi Alat dengan Alat Ukur Standar

Agar nilai pengukurannya sesuai dengan alat ukur standar, maka perlu dilakukan kalibrasi untuk membandingkan instrumen tersebut dengan instrumen standar, yaitu instrumen E4500 Laboratorium Enviro Shafeera Medan, yang berlokasi di Jamin Ginting, Kec. Medan Tuntungan, Medan. Alat ukur gambar "Gas Analyzer" seperti pada gambar 4.

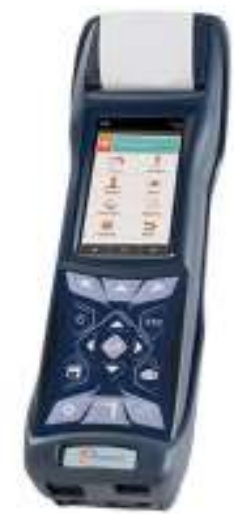

Gambar 4. E4500 Pendeteksi Gas

(Sumber Gambar: indomultimeter.com)

Setelah menyelesaikan alat desain kalibrasi digunakan untuk menguji emisi kendaraan bermotor dengan "e instruments E 4500" dengan hasil pengukuran dapat dilihat pada tabel 3.

Tabel 3. Perbandingan Data Alat Desain dengan Alat Ukur Standar

\begin{tabular}{ccccc}
\hline $\begin{array}{c}\text { Data Standar } \\
\text { (z) }\end{array}$ & $\begin{array}{c}\text { Data Sensor } \\
\text { (x) }\end{array}$ & $\boldsymbol{Y}=\mathbf{z}-\boldsymbol{x}$ & $\boldsymbol{x}-\overline{\boldsymbol{x}}$ & $(\boldsymbol{x}-\overline{\boldsymbol{x}})^{2}$ \\
\hline 647 & 650 & -3 & -12 & 144 \\
660 & 665 & -5 & 3 & 9 \\
667 & 671 & -4 & 9 & 81 \\
\hline$\sum(\boldsymbol{x}-\overline{\boldsymbol{x}})^{2}$ & & & & 234 \\
$\boldsymbol{\delta}=\sqrt{\frac{\sum(\boldsymbol{x}-\overline{\boldsymbol{x}})^{2}}{\boldsymbol{n}-\mathbf{1}}}=\sqrt{\frac{\mathbf{2 3 4}}{\mathbf{2}}}=\mathbf{1 0 . 8 1 6}$ \\
$\frac{\boldsymbol{U} \boldsymbol{A}_{\mathbf{1}}=\frac{\boldsymbol{\delta}}{\sqrt{\boldsymbol{n}}}=\frac{\mathbf{1 0 . 8 1 6}}{\sqrt{\mathbf{3}}}=\mathbf{6 . 2 4 5}}{}$
\end{tabular}

Pengujian alat ukur ini membandingkan nilai konsentrasi perangkat standar dengan perangkat yang dibuat dengan sumber gas yang sama. Dari tabel di atas, kita dapat menemukan nilai 
ketidakpastian hasil pengukuran $\left(\mathrm{UA}_{1}\right)$ dengan terlebih dahulu mencari nilai standar deviasi 10,816 dan nilai ketidakpastian 6,245.

Tabel 4. Tabel Nilai SSR pengujian

\begin{tabular}{lllll}
\hline $\mathbf{X ~ y}$ & \multicolumn{1}{c}{$\boldsymbol{x}^{\mathbf{2}}$} & \multicolumn{1}{c}{$\boldsymbol{Y}_{\text {reg }}$} & $\boldsymbol{R}$ & $\boldsymbol{R}^{\mathbf{2}}$ \\
\hline-1950 & 422500 & -3.229 & -0.229 & 0.052 \\
\hline-3325 & 442225 & -4.191 & $-0,809$ & 0.654 \\
\hline-2684 & 450241 & $-5,575$ & 0.575 & 0.331 \\
\hline$\sum \boldsymbol{x}=-\mathbf{7 9 5 9}$ & $\sum x^{2}=1314966$ & $\sum Y_{\text {Reg }}=-11.995$ & $\sum R=-24$ & $\sum R^{2}=1.037$ \\
\hline
\end{tabular}

Untuk menemukan nilai ketidakpastian pendekatan regresi $\left(\mathrm{UA}_{2}\right)$ harus tahu nilai-nilai a dan $\mathrm{b}$. Nilai $b$ dapat dicari dengan:

$$
\begin{gathered}
b=\frac{n \sum x y-\sum x \sum y}{n \sum x^{2}-\left(\sum x\right)^{2}}=\frac{3 x(-7959)-(1986 x(-12))}{(3 x 1314966)-3944196}=-0.0641 \\
=\bar{Y}-b \bar{x}=-4-(-0.0641 \times 662)=38.436
\end{gathered}
$$

untuk menemukan nilai $\mathrm{R}$ adalah

$$
Y_{\text {Reg }}=a+b x=38.436-0.0641 x
$$

Tabel 4 menunjukkan nilai dari Sum of Square Residual (SSR) yaitu 1.037. Sedangkan nilai ketidakpastian dari pendekatan regresi adalah 1,02.

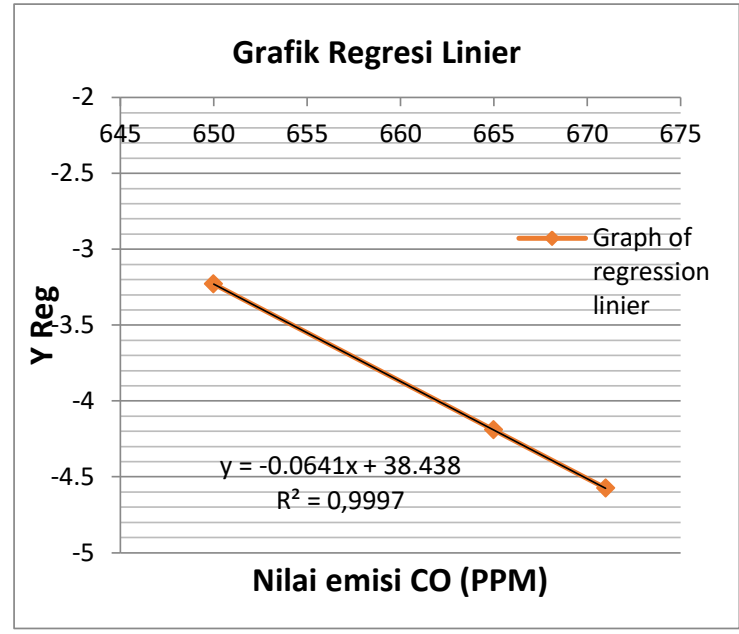

Gambar 5. Grafik regresi linear dari pengumpulan data karbon monoksida

Pada Gambar 5 hasil pengujian menggunakan sensor TGS 822 dibandingkan dengan alat CO meter diperoleh persamaan regresi $\mathrm{y}=-0,0641 \mathrm{x} \pm 38.438$ dengan nilai $\mathrm{R}^{2}=0.9997$. Nilai $\mathrm{R}^{2}$ yang besar menunjukkan korelasi yang kuat antara data dari meter CO dengan sensor TGS 822 .

\section{Simpulan}

Dari data hasil pengujian dan penganalisaan terhadap data yang telah diperoleh pada penelitian ini yaitu alat detektor emisi gas karbon monoksida (CO), maka didapatkan kesimpulan yaitu sebagai berikut

a. Persamaan regresi yang dihasilkan dalam hasil penguian adalah $\mathrm{y}=-0.0641 \mathrm{x}+38.438$ dengan nilai $\mathrm{R}^{2}$ sebesar 0,9997.

b. Nilai ketidakpastian dari pendekatan regresi adalah 1,02.

c. Berdasarkan nilai yang didapatkan dari pengujian sensor dan pengujian alat ukur, bahwa alat ukur emisi gas karbonmonoksida (CO) dapat bekerja dengan baik. 


\section{Referensi}

BBC News, 2019. The way the biggest cities in the world fight the smog. Diakses pada tanggal 20 Februari 2019 dari https://www.bbc.com/news/world-50287565

Juhara, Erwin. 2006 Demi Anak-Anak Kita Mengurangi Penggunaan Kendaraan Bermotor. Pikiran Rakyat Bandung

Mukono, H.J. 2011. Aspek kesehatan pencemaran udara. Surabaya: Airlangga University press.

Prabowo, K., \& Muslim, B. 2018. Penyehatan udara. Jakarta: Pusat Pendidikan Sumber Daya Manusia kesehatan

Pusat Data dan Informasi Kementerian Lingkungan Hidup dan Kehutanan. 2018. Indeks kualitas lingkungan 2017. Jakarta: Kementerian Lingkungan Hidup dan Kehutanan.

Putro, I. A. E., \& Abadi, I. 2012. Rancang bangun alat ukur emisi gas buang, Studi Kasus: Pengukuran Gas Karbon Monoksida ( Co ). Essay, 60111, 1-9.

Robert, 1993. Automotive band book,VDI Verlag Germany. Pages: 108 -184

Suyuti, Ansar. 2013. Web-based gas emission level monitoring of diesel power plant using multisensors. International Journal of Engineering and Innovative Technology (IJEIT) Volume 3 Issue 2.

WHO. 2019. Air Pollution. Diakses pada tanggal 20 Februari 2019 dari https://www.who.int/healthtopics/air-pollution 